\title{
Parameterization of the Interlingua in Machine Translation
}

\author{
Bonnie Dorr* \\ Institute for Advanced Computer Studies \\ A.V. Williams Building, Room 3157 \\ University of Maryland \\ College Park, MD 20742 \\ e-mail: bonnie@umiacs.umd.edu
}

\begin{abstract}
The task of designing an interlingual machine translation system is difficult, first because the designer must have a knowledge of the principles underlying crosslinguistic distinctions for the languages under consideration, and second because the designer must then be able to incorporate this knowledge effectively into the system. This paper provides a catalog of several types of distinctions among Spanish, English, and German, and describes a parametric approach that characterizes these distinctions, both at the syntactic level and at the lexical-semantic level. The approach described here is implemented in a system called UNITRAN, a machine translation system that translates English, Spanish, and German bidirectionally.
\end{abstract}

\section{Introduction}

What makes the task of designing an interlingual machine tranglation system difficult is the requirement that the translator process many types of language-specific phenomena while still maintaining language-independent information about the source and target languages. Given that these two types of knowledge (language-specific and languageindependent) are required to fulfill the translation task, one approach to designing a machine translation system is to provide a common languageindependent representation that acts as a pivot between the source and target languages, and to provide a parameterized mapping between this form and the input and output of each language. This is the approach taken in UNITRAN, a machine translation system that translates English, Spanish,

\footnotetext{
+This paper describes research done at the University of Maryland Institute for Advanced Computer Studies and at the MIT Artificial Intelligence Labo ratory. Useful guidance and commentary during the research and preparation of this document were provided by Bob Berwick, Gary Coen, Bruce Dawson, Klaudia Dussa-Zieger, Terry Gaasterland, Ken Hale, Mike Kashket, Jorge Lobo, Paola Merlo, James Pustejovsky, Jeff Siskind, Clare Voss, Amy Weinberg, and Patrick Winston.
}

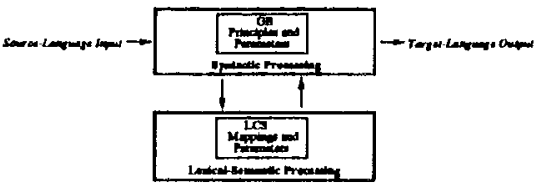

Figure 1: Overall Design of the UNITRAN System

and German bidirectionally. The pivot form that is used in this system is a lexical conceptual structure (henceforth, LCS) (see Jackendoff $(1983,1990)$, Hale \& Laughren (1983), Hale \& Keyser (1986a, 1986b), and Levin \& Rappaport (1986)), which is a form that underlies the source- and target-language sentences.

The pivot approach to translation is called interlingual because it relies on an underlying form derived from universal principles that hold across all languages. Within this framework, distinctions between languages are accounted for by settings of parameters associated with the universal principles. For example, there is a universal principle that requires there to be a conceptual subject for each predicate of a sentence. Whether or not the conceptual subject is syntactically realized is determined by a parameter associated with this principle: the null subject parameter. This parameter is set to yes for Spanish (also, Italian, Hebrew, etc.) but no for English and German (also French, Warlpiri, etc.). The setting of the null subject parameter accounts for the possibility of a missing subject in Spanish and the incorrectness of a missing subject in English and German (except for the imperative form).

This paper argues that, not only should the syntactic component of a machine translation system be parameterized, but other components of a machine translation system would also benefit from the parameterization approach. In particular, the lexicalsemantic component must be constructed in such a way as to allow principles of the lexicon to be parameterized. Thus, UNITRAN uses two levels of processing, syntactic and lexical-semantic, both of which operate on the basis of language-independent 
knowledge that is parameterized to encode language specific information (see figure 1).

Within the syntactic level, the language independent and language-specific information are supplied, respectively, by the principles and parumeters of government-binding theory (henceforth, GB) (Bee Chomsky (1981, 1982)). Within the lexical-semantic level, the language-independent and language-specific information are supplied by a set of general LCS mappings and the associated parameters for each language, respectively. The interface between the syntactic and semantic levels allows the source-language structure to be mapped systematically to the conceptual form, and it allows the target-language structure to be realized systematically from lexical items derived from the conceptual form. This work represents a shift away from cornplex, language-specific syntactic translation without entirely abandoning syntax. Furthermore, the work noves toward a model that emsloys a well-defined lexical conceptual representation without requiring a "deep" semantic conceptualization.

Consider the following exumple:

(1) (i) I stabbed John

(ii) Yo le di puñaladas a Juan

'I gave knife-wounds to John'

This example illustrates a type of distinction (henceforth called divergence as presented in Dorr (1990a)) that arises in machine translation: the sourcelanguage predicate, $s t a b$, is mapped to more than one target-language word, dar puñaladas a. This divergence type is lexical in that there is a word selection variation between the source language and the target language. Such divergences are accounted for by lexical-semantic parameterization, as we will see in section 3 .

The following section of this paper will provide a catalog of syntactic divergences between the source and target languages. The set of parameters that are used to account for these divergences will be degcribed. In the third section, we will exannine the divergences that occur at the lexical-semantic level, and we will see how the parametric approach accounts for these divergences as well. Finally, we will turn to the evaluation and coverage of the system.

\section{Toward a Catalog of Syntactic Divergences}

Figure 2 shows a diagram of the UNITRAN syntactic processing component. The parser of this component provides a mource-language syntactic structure to the lexical-semantic processor, and, after lexicalsemantic processing is completed, the generator of this component provides a target-language syntactic structure. Both the parser and generator of this component have access to the syntactic principles of GB theory. These principles, which act as constraints (i.e., filters) on the syntactic structures pro-

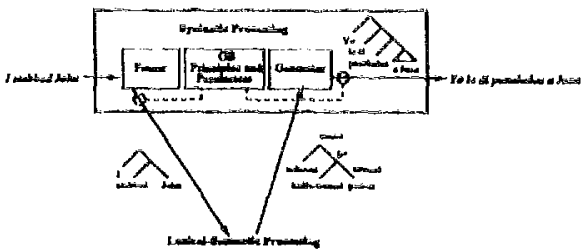

Figure 2: Design of the Syntactic Processing Com1ponent

duced by the parter and the generator, operate on the basis of parameter settings that supply certain language-specific information; this is where syntactic divergences are factored ont from the lexicalseinantic representation.

'The GH principles and parameters are organized into nodules whose constraints are applied in the following order: (1) $\widehat{\mathrm{X}}$, (2) Hounding, (3) Cast, (4) 'Irace, (5) Hinding, and (6) $\theta$. A detailed description of these nodules is provided in Dorr (1987). We will look briefly at a number of these, focusing on how syntactic divergences are accounted for by this approach. Figure 3 summarizes the syntactic divergences that are revealed by the parametric variations presented here. ${ }^{1}$

\subsection{Principles and Parameters of the $\bar{X}$ Module}

The $\overline{\mathrm{X}}$ constraint module of the syntactic component provides the phrase-structure representation of sentences. In particular, the fundumental principle of the $\bar{X}$ module is that each phrase of a sentence has a maximal projection, X-MAX, for a head of category $X$ (see figure 4 ) ${ }^{2}$ In addition to the head $X$, as phrasal projection potentially contains satellites $\alpha_{1}$, $\alpha_{2}, \beta_{1}, \beta_{2}, \gamma_{1}$, and $\gamma_{2}$, where $\alpha_{1}$ and $\alpha_{2}$ are any number of maximally adjoined adjuncts positioned according to the adjunction parameter, $\beta_{1}$ and $\beta_{2}$ are arguments (subjects and objects) ordered according to the constituent onder parameter, and $\gamma_{1}$ and $\gamma_{2}$ are any number of minimally adjoined adjuncts po sitioned according to the adjunction parameter. ${ }^{3}$

\footnotetext{
${ }^{1}$ The syntactic divergences are enmmerated with respect to the relevant parameters and nodules of the syntactic component. The figure illustrates the effect of syntactic parameter settings on the constituent gtructure for each language. (In this figure, F, stands for English, $\mathrm{Q}$ for German, S for Spanish, and I for lcelandic.)

'The possibilities for the category $X$ are: (V)erb, (N)oun, (A)djective, (P)reposition, (C)omplementizer, and (I)nflection. The Complementizer corresponds to relative pronouns auch as that in the man that $I$ sow. The Inflectional category corresponds to modals such as would in $I$ would eat cake.

${ }^{3}$ 'This is revised version of the $\overline{\mathrm{X}}$-'Theory presented in Chomsky (1981). 'The adjunction purameter will not be discusaed here, but Dorr (1987) for details.
} 


\begin{tabular}{|c|c|c|c|}
\hline \multicolumn{2}{|c|}{ Syntactsc Divergence Examples } & Parameter & GB Module \\
\hline $\begin{array}{l}\text { E, } \mathbf{~}: \\
\text { G: }\end{array}$ & $\begin{array}{l}\text { V precedes object } \\
\text { Vollows object }\end{array}$ & $\begin{array}{l}\text { constituent } \\
\text { order }\end{array}$ & $\overline{\mathbf{x}}$ \\
\hline $\begin{array}{l}\text { E! } \\
\text { S, G: }\end{array}$ & $\begin{array}{l}\text { P at randing allowed } \\
\text { No } P \text { at randing allowed }\end{array}$ & $\begin{array}{l}\text { proper } \\
\text { governors }\end{array}$ & Gov't \\
\hline $\mathbf{E}, \mathbf{G}:$ & $\begin{array}{l}\text { Fronted quettion word } \\
\text { beyond angle mentence } \\
\text { level not allowed } \\
\text { Fronted question word } \\
\text { beyond aingle sentence } \\
\text { level allowed }\end{array}$ & $\begin{array}{l}\text { bounding } \\
\text { nodes }\end{array}$ & Bounding \\
\hline$E, G:$ & $\begin{array}{l}\text { Thot required before } \\
\text { verbal object associ- } \\
\text { nted with clitic } \\
\text { P required before ver- } \\
\text { bal object } \\
\text { with clitic }\end{array}$ & $\begin{array}{l}\text { type of } \\
\text { government }\end{array}$ & Case \\
\hline $\begin{array}{l}E, G: \\
\text { S: }\end{array}$ & $\begin{array}{l}\text { Subject required in ma- } \\
\text { trix clause } \\
\text { Subject not required in } \\
\text { matrix clause }\end{array}$ & $\begin{array}{l}\text { null sub } \\
\text { ject }\end{array}$ & Trace \\
\hline E, S, G: & $\begin{array}{l}\text { Anaphor (e.g. him- } \\
\text { self) must have an- } \\
\text { tecedent inside near- } \\
\text { eat dominating clause } \\
\text { Antphor (e.g., siq) } \\
\text { may have antecedent } \\
\text { outside nesreat domi- } \\
\text { nating clause }\end{array}$ & $\begin{array}{l}\text { governing } \\
\text { entegory }\end{array}$ & Binding \\
\hline $\begin{array}{l}\text { S: } \\
\text { G: }\end{array}$ & $\begin{array}{l}\text { No empty pleonastics } \\
\text { allowed } \\
\text { Empty pleonastics al- } \\
\text { lowed } \\
\text { Empty pleonastics in } \\
\text { embedded clauses only }\end{array}$ & NDP & $\vec{\theta}$ \\
\hline
\end{tabular}

Figure 3: Summary of Syntactic Divergences

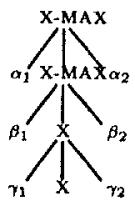

Figure 4: Phrase-Structure Representation

Given this general $\bar{X}$ phrase-structure representation, we can now "fit" this template onto the phrase structure of each language by providing the appropriate settings for the parameters of the $\bar{X}$ module For example, the constituent order parameter characterizes the word order distinctions among English, Spanish and German. Unlike English and Spanish, German is assumed to be a subject-object-verb language that adheres to the verb-second requirement in matrix clauses (see Safir (1985)). Thus, for the sentence I have seen him, we have the following contrasting argument structures:

(2) (i) I have seen him

(ii) Yo he visto a él 'I have seen (to him)'

(iii) Ich habe ihn gesehen 'I have him seen'

The $\overline{\mathrm{X}}$ module builds the phrase-structure from the general scheme of figure 4 and the parameter settings described above. The principles and param- eters of the remaining modules are then applied as constraints to the phrase-structure representation. We will now examine each of the remaining modules in turn.

\subsection{Principles and Parameters of the Government Module}

Government Theory is a central notion to the Case and Trace modules. A familiar example of the government principle in English is that a verb governs its object. ${ }^{4}$ We will examine the effect of this module in sections 2.4 and 2.5 .

\subsection{Principles and Parameters of the Bounding Module}

The Bounding module is concerned with the distance between pairs of co-referring elements (e.g., traceantecedent pairs). The fundamental principle of the bounding module is that the distance between coreferring elements is not allowed to be more than one bounding node apart, where the choice of bounding nodes is allowed to vary across languages.

The bounding nodes parameter setting accounts for a syntactic divergence between Spanish and English (and German):

(3) (i) * Who, did you wonder whether $t_{i}$ went to Bchool? $?^{5}$

(ii) ¿Quién $n_{i}$ crees tú que $t_{i}$ fue a la escuela?

The reason (3)(i) is ruled out is that the word who has moved beyond two bounding nodes. It turns out that the corresponding Spanisl sentence (3)(ii) is well-formed since the choice of bounding nodes is different and only one bounding node is crossed.

\subsection{Principles and Parameters of the Case Module}

The Case module is in charge of ensuring that all noun phrases are properly assigned abstract case (e.g., nominative, objective, etc.). The Case Filter rules out any sentence that contains a non-casemarked noun phrase.

The notion of government is relevant to case assignrnent since an element assigns case only if it is a governing case-assigner. The setting of the type of government parameter for English, Spanish, and German characterizes the following divergences:
(4) (i) I saw Guille * I saw to Guille
(ii)* Lo vi Guille Lo vi a Guille
(iii) Ich sah Guille * Ich sah zu Guille

\footnotetext{
See Dorr (1987) for a more formal definition of the government principle.

${ }^{s}$ If who is spoken emphatically, this sentence can almost be understood as an echo question corresponding to the statement $I$ wondered whether John went to school.
} 


\subsection{Principles and Parameters of the Trace Module}

After case has been assigned, the Trace module applies the empty category principle (ECP) which checks for proper government of empty elements. The ECP is parameterized by means of the null $s u b$ ject parameter. As discussed in section 1 , the null subject parameter accounte for the null subject distinction between Spanish, on the one hand, and linglish and German on the other:

(5) (i) Yo vi el libro Vi el libro

(ii) I saw the book * Saw the book

(iii) Ich saht das Buch * Sah das Buch

An additional parameter that is relevant to the Trace module is the proper governors parameter. The choice of proper governor accounts for preposition-stranding distinctions in the three languages:

(6) (i) [N.max What store] did John go to $t_{i}$ ?

(ii)* [N.max Cuál tienda]; fue Juan a $t_{i}$ ?

(iii)*[N.max Welchern Geschäft], geht Johanm zu $t_{i}$ ?

\subsection{Principles and Parameters of the Binding Module}

The Binding module is the final module applied before thematic roles are assigned. This module is concerned with the coreference relations among noun phrases, and it is dependent on the governing category parameter, which specifies that a governing category for a syntactic constituent is (roughly) the nearest dominating clause that has a subject. 'Ihis parameter happens to have the same setting for linglish, Spanish, and German, but see Dorr (1987) for a description of other settings of this parameter (e.g., for Icelandic) based on work by Wexler \& Manzini (1986).

\subsection{Principles and Parameters of the $\theta$ Module}

The $\theta$ module provides the interface between the syntactic component and the lexical-8emantic component. In particular, the assignment of thematic roles (henceforth $\theta$-roles) after parsing leads into the construction of the interlingual form.

The fundamental principle of the $\theta$ module is the $\theta$-Criterion which states that a lexical head must

${ }^{\circ}$ As noted in Jaeggli (1981), animate objects (e.g., Guille) are associated with a clitic pronoun (e.g., lo) only in certuin dialects such as that of the River Plate area of South America.

${ }^{T}$ The $t_{i}$ constituent is a trace that corresponds to the noun phrage that has been moved to the front of the sentence.

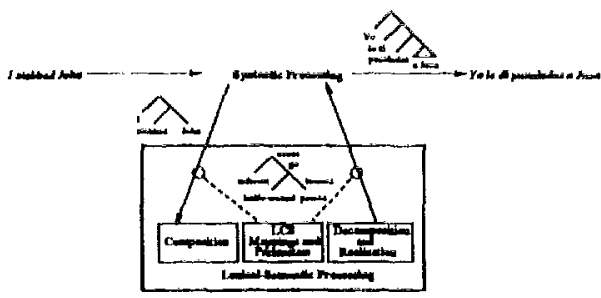

Figure 5: Design of the lexical-Semantic Component

assign $\theta$-roles in a unique one-to-one correspondence with the argument positions specified in the lexical entry for the head. One of the parameters associated with the $\theta$ module is the nom-drop paradigm (NDP) parameter (based on work by Safir (1985)). This parameter accounts for the distinction between Fnglish, on the one hand, and Spanish and German, on the other hand, with respect to the subject of an embedded clause:

(7) (i) * I know that was dancing

(ii) Yo sé que había un baile

'I know that (there) was a dance'

(iii) Ich weil, daß getanzt wurde 'I know that (there) was dancing'

Once all $\theta$-roles are assigned, the lexical-semantic component of the translator composes the interlingual representation for the source and target language. 'The next section will describe the lexicalsemantic component, and it will show how this component accounts for a number of divergences outside of the realm of syntax.

\section{Toward a Catalog of Lexical-Semantic Divergences}

Figure 5 shows a diagram of the UNIT'RAN lexicalsemantic processing component. A detailed description of the lexical conceptual structure (LCS) which serves as the interlingua is not given here, but see Dorr (1990b) for further discussion. ${ }^{8}$

\footnotetext{
${ }^{8}$ In general, the LCS representation follows the format proposed by Jackendoff $(1983,1990)$ which views semantic representation as a subset of conceptual structurc. Jackendoff's approach includes such notions as Event and State, which are specialized into prinitives such as GO, STAY, BE, GO-EXT, and ORIENT. As ant example of how the primitive GO in used to represent sentence semantics, consider the following sentence:
}

(B) (i) The ball rolled toward Beth.

(ii) Livens GO ([Thirg BALL],

$$
\text { [Path To }
$$$$
\text { ([Thing BALI.], [Thing BETH]))])] }
$$

This representation illustrates one dimension (i.e., the spatial dimension) of Jackendoff's representation. Another dimension is the causal dimension, which includes 


\begin{tabular}{|c|c|c|c|}
\hline \multicolumn{2}{|c|}{$\begin{array}{l}\text { Lexical-Semantic } \\
\text { Divergence Bxampies }\end{array}$} & $\begin{array}{l}\text { Divergence Type } \\
\text { (Parameter) }\end{array}$ & $\begin{array}{l}\text { Associated } \\
\text { Principle }\end{array}$ \\
\hline $\begin{array}{l}\mathrm{E}: \\
\mathrm{S}: \\
\mathrm{G}:\end{array}$ & $\begin{array}{l}\text { enter: John entered } \\
\text { the houme } \\
\text { entrar: Juan entro } \\
\text { en la cann } \\
\text { (hinesn)treten: Jo- } \\
\text { hann trat ins Haus } \\
\text { hinein }\end{array}$ & $\begin{array}{l}\text { Structural } \\
(*)\end{array}$ & $\begin{array}{l}\text { Linking } \\
\text { rule }\end{array}$ \\
\hline $\begin{array}{l}\text { E: } \\
S: \\
\text { G: }\end{array}$ & $\begin{array}{l}\text { Rke: Thke Mary } \\
\text { gustar: Me gusta } \\
\text { Marí } \\
\text { gefallen: } \\
\text { gefallt mis }\end{array}$ & $\begin{array}{l}\text { Thematic } \\
\text { (:INT, :EXT) }\end{array}$ & $\begin{array}{l}\text { Tinking } \\
\text { rule }\end{array}$ \\
\hline $\begin{array}{l}\mathbf{E}: \\
\mathbf{S}\end{array}$ & $\begin{array}{l}\text { be: I am hungry } \\
\text { sener: Yo tengo } \\
\text { hambre } \\
\text { haten: Ich habe } \\
\text { Hunger }\end{array}$ & $\begin{array}{l}\text { Gategorial } \\
\text { (:CAT) }\end{array}$ & $\mathrm{CSR}$ \\
\hline $\begin{array}{l}\mathbf{E} \\
\mathbf{S} \\
\mathbf{G}\end{array}$ & $\begin{array}{l}\text { The: Thke eating } \\
\text { gustar: Me gusta } \\
\text { comer } \\
\text { gern: Ich gern }\end{array}$ & $\begin{array}{l}\text { Demotional } \\
\text { (:DEMOTE) }\end{array}$ & $\begin{array}{l}\text { Tinking } \\
\text { rule }\end{array}$ \\
\hline $\begin{array}{l}\mathbf{E}: \\
\mathbf{S}: \\
\mathbf{G}:\end{array}$ & $\begin{array}{l}\text { usually: John usu- } \\
\text { ally goes home } \\
\text { soler: Juan quele ir } \\
\text { n casa } \\
\text { gewöohnhich: Johann } \\
\text { geht gewöhnlich } \\
\text { nach Haune }\end{array}$ & $\begin{array}{l}\text { Promotional } \\
\text { (:PFOMOTE) }\end{array}$ & $\begin{array}{l}\text { Linking } \\
\text { rule }\end{array}$ \\
\hline $\begin{array}{l}\mathbf{E}: \\
\mathbf{S}: \\
\mathbf{G}:\end{array}$ & $\begin{array}{l}\text { stab: latabbed John } \\
\text { dar: Yo le di } \\
\text { puñaladas a Juan } \\
\text { erstechen: Ich er- } \\
\text { atach Johann }\end{array}$ & $\begin{array}{l}\text { Confiational } \\
\text { (:CONFLATED) }\end{array}$ & $\begin{array}{l}\text { Linking } \\
\text { rule }\end{array}$ \\
\hline
\end{tabular}

Figure 6: Summary of Lexical-Semantic Divergences

What is important to recognize about this processing component is that, just as the syntactic component relies on parameterization to account for source-to-target divergences, so does the lexicalsemantic component. The parameterization of this component is specified by means of language-specific lexical override markers associated with the LCS mapping between the syntactic structure and the interlingua.

We will look briefly at the principles and parameters of the lexical-semantic component, focusing on how a number of divergences are accounted for by this approach. Figure 6 summarizes the lexicalsemantic divergences that are revealed by the parametric variations presented here. ${ }^{9}$

the primitives CAUSE and LET. A third dimension is introduced through the notion of field. This dimension extends the semantic coverage of spatially oriented primitives to other domains such as Possessional, Temporal, Identificational, Circumstantial, and Existential.

${ }^{9}$ The divergences are enumerated with respect to the relevant principles and parameters of the lexicalsemantic component. In contrast to the summary of syntactic divergences in figure 3 , which enumerates the effect of syntactic parsmeter settings on constituent structure, the list of divergences presented here is specified in terms of the effect of LCS parameter settings on the realization of specific lexical items.
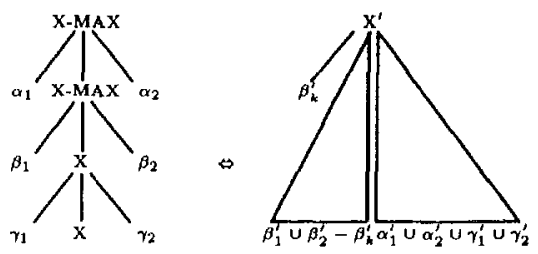

1. Syntactic opecifler $\left(\beta_{k} \in \beta_{1} \cup \beta_{2}\right)$ $\Leftrightarrow$ I ogical subject $\left(\beta_{N}^{t}\right)$

2. Syntactic complements $\left(\theta_{1} \cup \beta_{2}-\beta_{k}\right)$
$\Leftrightarrow$ Logical arguments $\left(\beta_{1}^{y} \cup \beta_{2}-\beta_{k}\right)$

3. Syntactic adjuncts $\left(\alpha_{1} \cup \alpha_{2} \cup \gamma_{1} \cup \gamma_{2}\right)$

$\Leftrightarrow$ Irogical Modiflere $\left(\alpha_{1}^{\prime} \cup \alpha_{2}^{\prime} \cup \gamma_{1}^{\prime} \cup \gamma_{2}^{\prime}\right)$

4. Synactic head $(X)$

$\Leftrightarrow$ Logical head $\left(X^{\prime}\right)$

Figure 7: ICS Linking Rule Between the Syntactic Structure and the Interlingua

\begin{tabular}{|l|c|}
\hline LCS Tupe & Syntactic Category \\
\hline EVRNT & $\mathrm{V}$ \\
\hline STATE & $\mathrm{V}$ \\
\hline THING & $\mathrm{N}$ \\
\hline PROPERTY & $\mathrm{A}$ \\
\hline PATH & $\mathrm{P}$ \\
\hline POSITION & $\mathbf{P}$ \\
\hline LOCATION & $\mathbf{A D V}$ \\
\hline TIME & $\mathrm{ADV}$ \\
\hline MANNER & ADV \\
\hline INTENSIFIER & ADV \\
\hline PURPOSE & ADV \\
\hline
\end{tabular}

Figure 8: $\mathcal{C S R}$ Correspondence Between LCS Type and Syntactic Category

\subsection{Principles and Parameters of the Lexical-Semuntic Component}

The algorithm for mapping between the syntactic structure and the interlingua relies on the output of $\theta$-role assignment (in the analysis direction) and feeds into $\theta$-role assignment (in the synthesis direction). The $\theta$-roles represent positions in the LCS representations of lexical entries associated with the input words. Thus, the construction of the interlingua is essentially a unification process that is guided by the pointers left behind by $\theta$-role assignment.

The mapping, or linking rule between the syntactic positions and the positions of the LCS representation is shown in figure 7 . In terms of $\theta$-role assignment, the phrasal head $\mathrm{X}$ assigns $\theta$-roles corresponding to positions in the LCS associated with $X^{\prime}$. For example, the syntactic subject $\beta_{k}$ is assigned the logical subject position $\beta_{k}^{\prime}$ in the LCS. Once all these roles have been assigned, the interlingual representation is composed simply by recursively filling the arguments of the predicate into their assigned LCS positions. 
In addition to the ICCS linking rule, there is another general rule associated with the lexicalsemantic component: the canonical syntactic representation (CSR) function. This function associates an LCS type (e.g., THIw) with a syntactic calegory (e.g., N-MAX) (see figure 8).

The LCS linking rule and the $\mathcal{C S} \mathcal{R}$ function are the two fundanental principles of the lexicalsemantic component. In urder to account for lexicalsemantic divergences, these principles must be parameterized. In general, translation divergences occur when there is an exception to one (or both) of these principles in one language, but not in the other. 'Thus, the lexical entries have been constructed to support parametric variation that accounts for such exceptions. The paratneters are used in lexical entries as overrides for the I.CS linking rule and $C S R$ function. We will now exarnine examples of how each parameter is used.

\section{1 .1 ' Parameter}

'The '*' parameter refers to an LCS position that is syntactically realizable in the surface sentence. 'This; parameter accounts for struciural divergence:

(9) (i) John entered the house

(ii) Juan entró en là casa

'John entered (into) the house'

Here, the Spanish sentence diverges structurally from the English sentence since, the noun phrase (the hotse) is realized as a prepositional phrase (en la casa). In order to account for this divergence, the lexicon uses the * marker in the LCS representation associated with the lexical entries for enter and entrar. This marker specifies the phrasal level at which an argument will be projected: in the Spanish lexical entry, the marker is associated with an ICS position that is realized at a syntactically higher phrasal level than that of the English lexical entry.

\subsection{2 :IN'T and :EX'I Ptirametors}

The :INT and :HX'I paraneters allow the I,CS linking rule to be overridden by associating a logical subject with a syntactic complement and a logical argument with a syntactic subject. A possible effect of using these parameter settings is that there in it subject-object reversal during translation. Such a reversal is called a thernatic divergence:

(10) (i) I like Mary

(ii) Me gusta María

'Mary pleases tine'

Here, the subject of the source-language sentence, $I$, is translated into an object position, and the object of the source-language sentence Maria is translated into a subject position. In order to account for this divergence, the lexicon uses the :INI' and : $\mathrm{EXT}$ markers in the ICS representation associated with the lexical entries for gustar. The Higlish lexical entry does not contain these markers since the I,CS linking rule dots not need to be overridden in this case.

\subsection{3 :CAT Paraneter}

'The :SAT' marker provides a syntactic category for an LCS argunent. Recall that the $\mathcal{C S} R$ function majs an ICCS type to a syntactic category (sec figure 8). When this mapping is to be overridden by a lexical entry, the language-specific marker :CAT' is used.

'This parameter accounts for categorial divergence:
(11) (i) I am hungry
(ii) Ich habe Hunger
'I have liunger'

Here, not only are the predicates be and haben lexically distinct, but the arguments of these two predicites are categorially divergent: in English, the argument is an adjectival phrise, and, in German, the argument is a noun phrase. 'The :CA'T marker is used in the German definition to force the PnopERTY argunent to be retalized as a noun rather than an adjective. Thus, the $\mathcal{G R}$ function is overridden during realization of the word IIuger in this exam ple.

\subsection{4 :DEMOTE and :PROMOTE "arumeter"s}

T'he :I)FMO'TF and :PROMOTE markers, like the :INT and :LX'I markers, allow the LCS linking rule to be overridden by associating a logical head with a syntactic adjunct or complement. These parameters account, respectively, for demotional divergence:

(12) (i) I like to cat

(ii) Ich esse; gern 'I eat likingly"

and promotional divergence:

(13) (i) Jolin usially goes houne

(ii) Juall suele ir a casa

'Jolut tends to go home'

In the first case, the English main verb like corresponds to the adjunct gerte in German, and the embedded verb eat corresponds to the main verb essen in German. In the second case, the Hinglish adjunct usually corresponds to the main verb soler in Spanish. "These "Isearl switching" divergences are accommodated analogously: the :DEMO'TE marker is used in the lexical entry for gern and the :PROMO'lly siser is used in the lexical entry for soler.

\subsection{5 : CONFIATED Parameter}

The sixth ICS parimeter is the :CONFIAATED matker. 'This marker is used for indicating that a proticular argunent need not be realized in the unrlace representation. This parameter accounts for conflational divergence as in the sentence $I$ stabbed Johin (ues (1) from section 1). In this exarnple, the 


\begin{tabular}{|c|c|}
\hline Clas of Verb & Lexical primitives \\
\hline Poition & $\begin{array}{l}\text { STRYTEMP, STRY-LOC, BETEMP, } \\
\text { BE.LOC }\end{array}$ \\
\hline Change or Pontion & GOLOC, GO-TEMP \\
\hline Dírected Motion & OOLLC, GO.POSS \\
\hline Motion with Manues & Go.LOC \\
\hline Exchange & CXUSE.EXCHANGE \\
\hline Phyilcalstate & BE-IDENT, STAY-IDENT \\
\hline $\begin{array}{l}\text { Change of Phyaical } \\
\text { State }\end{array}$ & GO-IDENT \\
\hline Orisntation & ORIENT-1OC \\
\hline Exitience & DE-EXIST, GO-EXIST, STAY-EXIST \\
\hline Circumatance & HE.CTKC, GO.CIRC, STAY.CIRC \\
\hline Ratge & $\begin{array}{l}\text { GO.EXT-IDENT, GO-EXT.TEMP, } \\
\text { GO-EXT-LOC }\end{array}$ \\
\hline Tntention & OAIENT-CIRC, OFIENT-TEMP \\
\hline Owhership & DE.POSS, STAY.POSS \\
\hline Poych State & DE-IDENT \\
\hline $\begin{array}{l}\text { Perception and } \\
\text { Communication }\end{array}$ & "НEAKTPEK, SEE-PERC \\
\hline Mental Froceos: & DE.PERC, GO.PERC \\
\hline Cosi & OHIENT-IDENT \\
\hline Losdspray & Go.LOC \\
\hline Contact/bfeat & GO-POSS \\
\hline
\end{tabular}

Figure 9: Coverage of Lexical-Semantic Primitives

argument that is incorporated in the English sentence is the KMIFE-WOUnD argument since the verb stab does not realize this argument; by contrast, the Spanish construction dar puñaladas a explicitly realizes this argument as the word punaladas. Thus, the :CONFLATED marker is associated with the xwrFE-Wound argument in the case of stab, but not in the case of dar.

\section{Evaluation and Coverage}

One of the main criteria used for evaluation of the parameterization framework described here is the ease with which lexical entries may be automatically acquired from on-line resources. While testing the framework against this metric, a number of results have been obtained, including the discovery of a fundamental relationship between the lexical-semantic primitives and aspectual information. 'This relationship is crucial for demonstrating the success of the parameterization approach with respect to lexical acquisition. Details about the lexical acquisition model and results are presented in Dorr (1992).

We have already examined the syntactic and lexical-semantic coverage of the system (see figures 3 and 6 above). The linguistic coverage of the lexicon is summarized in figure 9 .

\section{Conclusion}

The translation model described here is built on the basis of a parametric approach; thus, it is easy to change from one language to another (by setting syntactic and lexical switches for each language) without having to write a whole new processor for each language. This is an advance over other machine translation systems that require at least one language-specific processing module for each sourcelanguage/target-language pair.
The approach is interlingual: an underlying language-independent form of the source language is derived, and any of the three target languages, Spanish, English, or German, can be produced from this form. Perbaps the most important advance of UNITRAN is the mapping between the lexical-semantic level and the syntactic level. In particular, the system has been shown to select and realize the appropriate target-language words, despite the potential for syntactic and lexical divergences. The key to being able to provide a systematic mapping between languages is modularity: because the system has been partitioned into two different processing levels, there is a decoupling of the syntactic and lexicalsemantic decisions that are made during the translation process. Thus, syntactic and LCS parameter settings may be specified for each language without hindering the processing that produces, and generates from, the interlingual form.

\section{References}

Chomsky, Noum A. (1981) Lectures on Government and Binding, Foris Publicationa, Dordrecht.

Chomaky, Noam A. (1982) "Some Concepts and Consequences of the Theory of Government and Binding," MIT Presi.

Dorr, Bonnie J. (1987) "UNITRAN: A Principle-Baned Approach to Machine Tranalation," AI Technical Report 1000, Master of Science thesia, Department of Electrical Engineering and Computer Science, Mauachusetts Institute of Technology.

Dorr, Bonnie J. (1990a) "Solving Thematic Divergences in Machine Tranalation," Procedings of the 28th Annual Confer. ence of the Association for Computational Linguistics, University of Pittsburgh, Pittmburgh, PA, 127-134.

Dorr, Bonnie J. (1990b) "A Cros-Linguistic Approach to Machine Trandation," Proceedings of the Third International Conference on Theoretical and Methodological Issues in Ma. chine Translation of Natural Languages, Linguistica Research Center, The Univeraity of Texan, Austin, TX, 13-32.

Dorr, Bonnie J. (1992) "A Parameterized Approach to Integrating Aspect with Lexical-Semantic for Machine Tranulation" Proceedings of the Soth Annual Conference of the Associa. tion for Gomputational Lingustics, University of Delaware, Newark, DE.

Hale, Kenneth and M. Laughren (1983) "Warlpiri Lexicon Project: Warlpiri Dictionary Entries," Massachusetta Institute of Technology, Cambridge, MA, Warlpiri Lexicon Project.

Hale, Kenneth and Jay Keyser (1986a) "Some Tranaitivity Alternations in Engliah" "Center for Cognitive Science, Massachusetts Institute of Technology, Cambridge, MA, I,exicon Project Working Papers \#7

Hale, Kenneth and J. Keyser (1986b) "A View from the Middle," Center for Cognitive Science, Massachusetts Institute of Technology, Cambridge, MA, Lexicon Project Working Papera \#10.

Jackendoff, Ray S. (1983) Semantics and Cognition, MIT Press, Cambridge, $\mathrm{MA}$.

Jackendof, Ray S. (1990) Semantic Structures, MIT Prese, Cambridge, MA.

Jaeggli, Orvaldo Adolfo (1981) Topics in Romance Syntax, Foris Publications, Dordrecht, Holland/Cimnarninson, USA.

Levin, Beth and Malka Rappapart (1986) "The Formation of Adjectival Pasaiven," I,inguistic Inquiry 17, 623-662.

Saflr, Ken (1985) "Misaing Subjects in German," in Studies in German Grammar, Toman, Jindfich (ed.), Foris Publications, Dordrecht, Hollnnd/Cinnamineon, USA, 193-229.

Wexler, Kenneth and M. Rita Manzini (1986) "Parametera and Learnability in Binding Theory," presented at the Cognitive Science Seminar, MIT, September, Cambridge, MA.

Zubizarreta, Moria Luisa (1987) Levels of Representation in the Lexicon and in the $S_{y n t a x}$ Foris Publications, Dordrecht, Holland/Cinnaminoon, USA. 